\title{
Prevalence and risk determinants of HIV-1 and HIV-2 infections in pregnant women in Bissau ${ }^{\text {मh }}$
}

\author{
Erika Gianelli ${ }^{a, *, 1}$, Agostino Riva ${ }^{a, 1}$, Fanny A. Rankin Bravo ${ }^{\text {b }}$, \\ David Da Silva Te ${ }^{b}$, Enrica Mariani ${ }^{b}$, Giovanni Casazza ${ }^{d}$, \\ Chiara Scalamogna $^{a}$, Oscar Bosisio ${ }^{b}$, Fulvio Adorni ${ }^{c}$, Stefano Rusconi ${ }^{a, 1}$, \\ Massimo Galli ${ }^{\text {a }}$
}

${ }^{a}$ Infectious Diseases and Immunopathology Section, Department of Clinical Sciences, University of Milan, L. Sacco Hospital, Via GB Grassi 74, 20157 Milano, Italy

${ }^{\mathrm{b}}$ Associaçao Céu e Terras, Guinea-Bissau, West Africa

' Institute of Biomedical Technologies, National Research Council, Segrate, Milan, Italy

${ }^{\mathrm{d}}$ Institute of Medical Statistics and Biometry, University of Milan, Italy

Accepted 31 August 2010

Available online 8 September 2010

\section{KEYWORDS \\ HIV-1; \\ HIV-2; \\ Epidemiology; \\ Pregnant women; \\ Guinea-Bissau}

\begin{abstract}
Summary Objectives: To analyse the risk determinants of HIV-1 and HIV-2 infections in pregnant women in Bissau.

Methods: Pregnant women attending the antenatal clinics of Bissau between January 2002 and June 2006 were consecutively tested unless they opted out.

Results: Among 23,869 tested women the overall prevalence of HIV-1 was $5.7 \%$, that of HIV-2 was $2.4 \%$, and these included the $0.7 \%$ prevalence of HIV-1 and HIV-2 duals. The main factors associated with the risk of HIV-1 infection were older age, occupation and number of sexual partners. Beafada and Mandinga ethnic groups were at greater risk of presenting HIV-1, and Bijago and Papel at lower risk. The factors associated with the risk of HIV-2 were age, literacy and occupation; the Beafada were at greater risk than the other ethnic groups.

Conclusions: The prevalence of HIV-2 infection decreased overtime, whereas that of HIV-1 infection remained substantially stable, but was higher than that observed in previous studies. The rapid decline in the rates of HIV-2 infection suggests that many of the factors that allowed its exponential growth in the past have now been partially removed, and that sexual and vertical transmission have not been sufficient to maintain and extend the epidemic. (c) 2010 The British Infection Society. Published by Elsevier Ltd. All rights reserved.
\end{abstract}

\footnotetext{
Presented as a poster at the15th Conference on Retroviruses and Opportunistic Infection, Boston, MA (USA), February 2008.

* Corresponding author. Tel.: +3902 39042451; fax: +390250319758.

E-mail addressess: erkgianelli@gmail.com (E. Gianelli), agostino.riva@unimi.it (A. Riva), stefano.rusconi@unimi.it (S. Rusconi).

1 These authors equally contributed to the work.
} 


\section{Introduction}

Guinea-Bissau is one of the few sub-Saharan African countries in which the rates of both HIV-1 and HIV-2 infections have reached significant levels. ${ }^{1-4}$

Molecular analysis suggests that HIV-2 emerged about 1940s and increased exponentially after $1955^{5}$ to reach the highest prevalence in the world. ${ }^{2,6-8}$ It is thought that the long war that ravaged the country from 1963 to 1974 increasing the risk of sexual abuse and promiscuity, parenteral transmission through female ritual excision and multiple injections for the treatment of tuberculosis and the prevention of trypanosomiasis significantly contributed to its spread, ${ }^{1,2,9}$ but its prevalence is now declining ${ }^{10-12}$ The reasons for this decline are not clear as various data converge to show that survival is longer in patients infected with HIV-2 than in those infected with HIV-1, and that a larger percentage of HIV-2 infected individuals become long-term non-progressors ${ }^{13,14}$ and therefore potentially contribute to the spread of the infection for a long time. On the other hand, the modest genital shedding of HIV-2 $2^{15-17}$ probably reduces the efficiency of sexual transmission, as suggested by the considerably slower spread of HIV-2 among sex workers $^{16,18}$ and the marked reduction in HIV-2 in Angola and Mozambique at the end of 1990s. ${ }^{1}$

HIV-1 in Guinea-Bissau is mainly represented by the A/G (CRF 02_AG) recombinant strain, ${ }^{19,20}$ and the finding of clusters, which contained sequences separated by short branches, suggests that the virus had time to evolve in the country. ${ }^{20}$ However, it is likely that HIV-1 arrived some years after HIV-2 as it was completely absent in a study population already showing a significant prevalence of HIV-2 in 1980s, ${ }^{21}$ and was first documented in three out of 2539 pregnant women $(0.1 \%)$ by Månsson et al. in 1988. ${ }^{22}$ Interestingly, this study (which tested 20,422 pregnant women in Bissau between 1982 and 2004) found that the prevalence of HIV-2 was $8.3 \%$ in 1987 and decreased to $1.9 \%$ in 2004 , whereas the prevalence of HIV-1 increased and passed $4 \%$ in 1999 . It has been suggested that the civil war in 1998-1999 played a role in spreading HIV-1 infection. $^{22}$

This study data collected during a programme for the prevention of mother-to-child transmission (PMTCT) of HIV-1 infection in Bissau City between 2002 and 2006 provides further information concerning the trend of the two HIV infections, and has allowed us to speculate on the factors associated with the risk of HIV infection.

\section{Materials and methods}

The study started in ten public antenatal clinics (ANCs) in Bissau City in 2002 with the ethical approval of the Scientific Committee of the Ministry of Public Health of Guinea-Bissau. The study was part of a Nevirapine (NVP) based PMTCT program offered to all HIV-1 infected women. Both HIV-1 and HIV-2 infected women were also offered free artificial feeding and nutritional support. All pregnant women attending the ANCs were invited to participate in a voluntary counselling and testing programme by local counsellors. During the counselling, a nurse completed a questionnaire covering age, ethnic group, school attendance, profession, marital status, the number of sexual partners in the year preceding the study, and the number of previous pregnancies (excluding abortions and stillbirths).

When no personal documents or official registrations were available, the date of birth or presumptive age was assessed on the basis of the indications given by the women. When their parents belonged to different ethnic groups, the women were allowed to define themselves as being of 'mixed' ethnicity; the women were also allowed to define themselves as not belonging to any specific ethnic group. The women whose nationality was not GuineaBissauan formed a separate group. All of the women were asked to state their previous school attendance; those who had never attended school and were unable to read the items of the questionnaire were defined 'illiterate'. Teachers, healthcare workers, traders, and public and private employees were grouped as 'professionals' and compared with students and housewives. Marital status was categorised as casada (regularly married), amigada (cohabitant or having a stable partner) and solteira (single, no stable partner reported). The nurse who filled the questionnaire was asked to evidence every item refused by the counselled woman.

The enrolled women were asked to give their informed consent to HIV testing and the use of their personal data to analyse the factors associated to risk of HIV-1 and HIV-2 infections. Before analyses, all data were made anonymous by using an alpha-numeric code.

A coding system based on name and date of birth was adopted by all the ANCs, and the data were entered in a centralised database.

\section{HIV testing}

If the woman accepted to be tested, a rapid test was performed as soon as possible during the first physical examination and the results were given immediately after.

HIV infection was detected using the WHO protocols for developing countries ${ }^{23}$ and two rapid screening tests: Capillus HIV-1/HIV-2 (Cambridge 5 Biotechnology, Galway, Ireland) (Sensitivity: 98.6-99.9\%, specificity: 98.2-99.6\%) or Genie II HIV-1/2 (BioRad Laboratories, Redmond, Washington, USA) (Sensitivity: 97.8-100\%, specificity: 99.7-100\%); an enzyme-liked immunosorbent assay (ELISA, BioRad Laboratories, USA) was used for confirmation.

\section{Statistical analysis}

Linear by linear association $\mathrm{X}^{2}$ test was used to determine the trend of HIV-1 and HIV-2 infections during the study period 2002-2006. Subjects with dual HIV-1/HIV-2 infections were included in both single HIV-1 and HIV-2 infected groups.

A logistic model was applied in order to compare the overall risk of HIV infection between the ethnic groups frequently practising excision and those which do not.

Univariate and multiple polytomous logistic regression analyses were used to analyse the associations between HIV positivity (dependent variable, classified as HIV-1, HIV-2, HIV-1/2 or HIV negative) and the independent variables, which included the sociodemographic data (age, literacy, 
occupation, marital status, the number of sexual partners, ethnic group, and the number of previous pregnancies) and the year of the test. For each sociodemographic factor and the year of testing, polytomous logistic regression models were used to estimate the odds ratios (ORs) of being HIV-1, HIV-2 or HIV-1/2 positive vs HIV negative (reference category), and their 95\% confidence intervals (Cls).

All of the independent variables in the multiple logistic regression analyses were forced to enter the model simultaneously; no variable (stepwise, forward or backward) selection procedure was applied.

All of the statistical analyses were made using SAS statistical software (version 9.1).

\section{Results}

Between January 1, 2002 and April 30, 2006, a total of 27,166 pregnant women attended the ANCs. Three hundred and sixty-nine of them (1.4\%) refused to participate; the percentage of refusals per calendar year did not change significantly during the study period (range 1.1-1.5\%). Agreement to participate was not actually followed by HIV testing in 2928 cases (10.81\%).

Table 1 shows the demographic characteristics of the 23,869 women (median age 23 years) who were actually counselled and tested for HIV-1 and HIV-2. The characteristics did not significantly change overtime. The women belonging to ethnic groups that accounted for fewer than $1 \%$ of the total (Cristão de Geba [60 women], Djacanca [44], Nhominca [28], Nalu [77], Saraculé [177] and Sussó [54]) were grouped together and defined as 'other', which also included the women whose ethnicity was unclear (1.7\%). The foreigners mainly came from Cape Verde (109, 0.5\%) and Senegal $(32,0.1 \%)$.

\section{HIV-1 and HIV-2 prevalence, and variations overtime}

Throughout the study period, testing showed that the HIV-1 infected women (including HIV-2 co-infected) were 1360 (5.7\%). The HIV-2 infected women (including HIV-1 coinfected) were 575 (2.4\%). HIV-duals were 170 (0.7\%).

Figure 1 shows the prevalence of HIV-1 and HIV-2 infections by calendar year. There was a significant decrease in the prevalence of HIV-2 ( $p=0.006)$ during the study period, but no significant change in the prevalence of HIV-1 infection.

The polytomous logistic regression in the univariate model revealed that the risk of a positive test was influenced by the calendar year of the test itself $(p=0.0010)$, but only the risk of co-infection significantly decreased per calendar year (OR 0.797; 95\% Cl $0.704-0.901)$. The multivariate model confirmed the influence of the calendar year of testing $(p=0.003)$ and the reduced risk of co-infection per calendar year (AOR 0.758, 95\% Cl 0.664-0.865) (Table 2).

\section{Age of testing and the risk of HIV infection}

The women were divided into four age groups (15-19, 20-24, $25-29$ and $\geq 30$ years); the youngest group, which accounted for $24.6 \%$ of the total, was taken as the reference category.
Age strongly influenced the risk of testing HIV positive in both the univariate $(p=0.0001)$ and multivariate models $(p=0.0001)$, with a clearly increased risk of HIV-1, HIV-2 and co-infection. Interestingly, the women aged $\geq 30$ years were more than six times more likely to be HIV-2 positive than those aged 15-19 years, and more than eight times more likely to be co-infected, whereas their risk of being HIV-1 positive was only twice as high.

\section{Occupation and the risk of HIV infection}

Just over $80 \%$ of the women were housewives, $2137(9.7 \%)$ defined themselves as students, and only 411 (1.7\%) were working (policewomen, clerks, teachers, art dealers and merchants) (Table 1). Nevertheless, working proved to be a significant correlate of the risk of HIV infection in the univariate model $(p=0.0001)$. In particular, the OR of the risk of HIV-1 infection was $2.011(95 \% \mathrm{Cl} 1.424-2.839)$ in professionals vs housewives, and students were at significantly lower risk of being HIV-2 positive than housewives (OR $0.352,95 \% \mathrm{Cl} 0.210-0.591$ ); both of these findings were confirmed by the multivariate analyses (Table 2). Univariate analysis showed that, in comparison with the housewives, the women who refrained to report their occupation were at higher risk of HIV-1 infection (OR 1.497, 95\% 1.244-1.802) and HIV-1/HIV-2 co-infection (OR $1.673,95 \% \mathrm{Cl} 1.072-2.610)$, and this was confirmed by the multivariate model (Table 2 ).

\section{Number of sexual partners and the risk of HIV infection}

As can be seen in Table 1, 74.1\% of the women declared they had only one sexual partner in the 12 months before enrolment. The number of partners significantly influenced the risk of HIV infection in the univariate model ( $p=0.0001)$. In particular, taking the group of women reporting only one partner as the reference category, the risk of HIV infection was $1.240(95 \% \mathrm{Cl} 1.059-1.453)$ in the group refraining from reporting the number of sexual partners and $1.416(95 \% \mathrm{Cl} 1.193-1.691)$ in the group reporting $\geq 2$ partners. In the univariate analyses the women reporting two or more partners were also at increased risk of HIV-2 infection (OR 1.472, 95\% Cl 1.116-1.943) and HIV-1/ HIV-2 co-infection (OR 2.156, 95\% Cl 1.464-3.176). The multivariate analyses confirmed the increased risk associated with the number of partners $(p=0.0005)$ and the increased risk of HIV-1 infection and HIV-1/HIV-2 co-infection in women reporting $\geq 2$ partners.

\section{Number of previous pregnancies and the risk of HIV infection}

$40.9 \%$ of the enrolled women had two or more previous pregnancies, while $38.6 \%$ were at first pregnancy (Table 1) The number of pregnancies significantly influenced the risk of infection in the univariate model $(p=0.0001)$. In particular, the risk of HIV-1 infection was higher in the women undergoing their second pregnancy (OR 1.428, 95\% $\mathrm{Cl} 1.222-1.670)$ and those reporting $\geq 2$ previous pregnancies (OR 1.281, 95\% Cl 1.119-1.467). The women with $\geq 2$ 
Table 1 Demographic characteristics and prevalence of HIV infection in 23,869 women enrolled in the study.

\begin{tabular}{|c|c|c|c|c|c|c|}
\hline & & HIV-1 & HIV-2 & HIV-1/2 & Negative & Total \\
\hline & & $N=1190$ & $N=405$ & $N=170$ & $N=22104$ & $N=23869$ \\
\hline & & $N$ (row\%) & $N$ (row\%) & $N$ (row\%) & $N$ (row\%) & $N$ (column\%) \\
\hline \multirow[t]{5}{*}{ Age (yr) } & $15-19^{e}$ & 169 (2.9) & $31(0.53)$ & $11(0.19)$ & $5618(96.38)$ & $5829(24.42)$ \\
\hline & $20-24$ & $437(5.33)$ & $102(1.24)$ & $46(0.56)$ & 7621 (92.87) & $8206(34.38)$ \\
\hline & $25-29$ & $349(6.03)$ & $118(2.04)$ & $55(0.59)$ & 5269 (90.99) & $5791(24.26)$ \\
\hline & $\geq 30$ & $220(5.71)$ & $151(3.92)$ & $53(1.38)$ & $3430(89.00)$ & $3854(16.15)$ \\
\hline & Missing & $15(7.93)$ & $3(1.60)$ & $5(2.64)$ & $166(87.83)$ & $189(0.79)$ \\
\hline \multirow[t]{2}{*}{ Literacy } & Illiterates e & $674(4.9)$ & $236(1.71)$ & $112(0.81)$ & $12747(92.58)$ & $13769(57.69)$ \\
\hline & Literates & $516(5.11)$ & $169(1.67)$ & $58(0.57)$ & 9357 (92.64) & $10100(42.31)$ \\
\hline \multirow[t]{4}{*}{ Occupation } & Housewife ${ }^{e}$ & $905(4.73)$ & $347(1.81)$ & $135(0.71)$ & 17752 (92.75) & $19139(80.18)$ \\
\hline & Professional $^{a}$ & $37(9.00)$ & $10(2.43)$ & $3(0.73)$ & 361 (87.83) & $411(1.72)$ \\
\hline & Students & $110(4.75)$ & $15(0.65)$ & $9(0.39)$ & $2183(94.22)$ & $2317(9.71)$ \\
\hline & NR & $138(6.89)$ & 33 (1.65) & 23 (1.15) & $1808(90.31)$ & 2002 (8.39) \\
\hline \multirow[t]{3}{*}{ Marital status } & Married ${ }^{\mathrm{e}}$ & $433(4.92)$ & $160(1.82)$ & $64(0.73)$ & $8150(92.54)$ & 8807 (36.9) \\
\hline & Amigada' b & $530(4.74)$ & $174(1.56)$ & 77 (0.69) & $10399(91.58)$ & $11180(46.84)$ \\
\hline & Single/NR & $227(5.85)$ & $71(1.83)$ & $29(0.75)$ & $3555(91.58)$ & $3882(16.26)$ \\
\hline \multirow{3}{*}{$\begin{array}{l}\text { Number of sexual } \\
\text { partners }\end{array}$} & $1^{e}$ & $820(4.64)$ & $291(1.65)$ & $109(0.62)$ & 16455 (93.10) & $17675(74.05)$ \\
\hline & $\geq 2$ & $168(6.35)$ & $62(2.34)$ & 34 (1.29) & $2381(90.02)$ & $2645(11.08)$ \\
\hline & NR & $202(5.69)$ & 52 (1.47) & $27(0.76)$ & $3268(92.08)$ & $3549(14.87)$ \\
\hline \multirow[t]{12}{*}{ Ethnic groups } & Balanta ${ }^{\mathrm{e}}$ & $275(4.78)$ & $103(1.79)$ & $33(0.57)$ & $5343(92.86)$ & $5754(24.11)$ \\
\hline & Beafada & $47(7.52)$ & $22(3.52)$ & $3(0.48)$ & $553(88.48)$ & $625(2.62)$ \\
\hline & Bijagos & $10(2.49)$ & $6(1.50)$ & $1(0.25)$ & $384(95.76)$ & $401(1.68)$ \\
\hline & Felupe & $22(4.25)$ & 7 (1.35) & $2(0.39)$ & 487 (94.02) & $518(2.17)$ \\
\hline & Fula & $214(4.86)$ & $71(1.61)$ & $36(0.82)$ & 4082 (92.71) & $4403(18.45)$ \\
\hline & Mancanha & $90(5.75)$ & $31(1.98)$ & $14(0.89)$ & $1430(91.37)$ & $1565(6.56)$ \\
\hline & Mandjaco & $89(4.84)$ & $28(1.52)$ & $15(0.82)$ & $1705(92.81)$ & $1837(7.70)$ \\
\hline & Mandinga & $135(6.46)$ & $36(1.72)$ & $17(0.81)$ & 1903 (91.01) & $2091(8.76)$ \\
\hline & Papel & $143(3.81)$ & $52(1.38)$ & $19(0.51)$ & $3542(94.30)$ & $3756(15.74)$ \\
\hline & Foreigners & $14(7.04)$ & 7 (3.52) & $1(0.50)$ & 177 (88.94) & $199(0.83)$ \\
\hline & Others $^{d}$ & $66(5.66)$ & $18(1.54)$ & $13(1.11)$ & $1069(91.68)$ & $1166(4.88)$ \\
\hline & NR & $85(5.47)$ & $24(1.54)$ & $16(1.03)$ & $1429(91.96)$ & $1554(6.51)$ \\
\hline \multirow[t]{3}{*}{ Previous pregnancies } & $0^{\mathrm{e}}$ & $389(4.22)$ & $90(0.97)$ & $47(0.51)$ & $8682(94.28)$ & $9208(38.58)$ \\
\hline & 1 & $289(5.90)$ & $57(1.16)$ & $30(0.61)$ & $4519(92.31)$ & $4895(20.51)$ \\
\hline & $\geq 2$ & $512(5.24)$ & $258(2.64)$ & $93(0.95)$ & $8913(91.27)$ & $9766(40.91)$ \\
\hline
\end{tabular}

\footnotetext{
NR: not responding.

a Including teachers, healthcare workers, traders, employees.

b Cohabitant with a stable sexual partners.

c in the last year.

d including "mixed" ethnicity and ethnic group accounting for $<1 \%$ of the total population.

e Reference category.
}

previous pregnancies were also at higher risk of HIV-2 infection (OR 2.796, 95\% Cl 2.196-3.561) and HIV-1/HIV-2 co-infection (OR 1.930, 95\% Cl 1.357-2.745). The multivariate model showed that the number of pregnancies $(p=0.0080)$ influenced the risk of HIV infection, but only confirmed a significantly increased risk for HIV-1 in women undergoing their second pregnancy in comparison with those at their first pregnancy (Table 2).

\section{Ethnic groups and the risk of HIV infection}

The Balantas were the most represented ethnic group (24.1\%), and were used as the reference category. The univariate and multivariate models both showed that the different ethnic groups were at significantly different risk of HIV infection ( $p=0.0001)$. The univariate analyses indicated that the risk of being infected with HIV-1 was higher among the Mandinga (OR 1.378, 95\% Cl 1.114-1.705) and Beafada (OR 1.651, 95\% Cl 1.197-2.277) and lower among the Papel (OR 0.784, 95\% Cl 0.639-0.964) and Bijago (OR $0.506,95 \% \mathrm{Cl} 0.267-0.959)$. The multivariate analyses confirmed all of these findings (Table 2).

Univariate analysis showed that the risk of HIV-2 infection was higher among the Beafada than among the Balanta (OR 2.066, 95\% Cl 1.293-3.300), and this difference was confirmed by the multivariate model. An increased risk of HIV-1/HIV-2 co-infection was found in women belonging to the ethnic groups accounting for fewer than $1 \%$ of the total sample and in women of unclear ethnicity, but this was not significant in the multivariate model. 


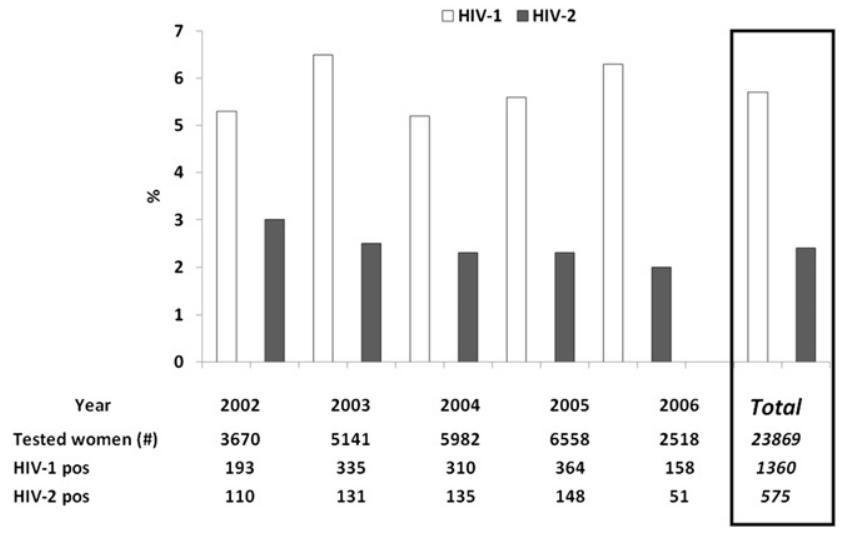

Figure 1 Prevalence of HIV-1 and HIV-2 in pregnant women in Guinea-Bissau, 2003-2006. The trend of HIV-2 infection was significantly decreasing (linear by linear association statistic $p=0.006$ ), while no significant variation was observed for HIV-1 and for the co-infection dual infected people $(n=170)$ are included in singly infected bars. The thicker continuous line indicates that the total bars are not the continuation of the time trend from 2002 to 2006.

A logistic model, comparing the overall risk of HIV infection between the ethnic groups frequently practising excision (Fula, Mandinga, Beafada, and Nalu) and those which do not (Balanta and Papel), showed that the former had a risk of $1.33(95 \% \mathrm{Cl} 1.09-1.64, p=0.008)$ for HIV-2 and a risk of $1.38(95 \% \mathrm{Cl} 1.2-1.59, p<0.0001)$ for HIV-1.

\section{Discussion}

Our findings confirm the previously reported decline in the prevalence of HIV-2 in Guinea-Bissau. ${ }^{11,12,22}$

In a recent study, Schmidt et al. used a mathematical model to evaluate the putative role of temporary changes in sexual behaviour and the competitive role of HIV-1 as a factor determining HIV-2 decline. ${ }^{24}$ Assuming that the competitive reduction induced by HIV-1 was $30 \%$, the prevalence of HIV-2 in women aging less then 45 years should have been about 3\% in 2005 and $2.5 \%$ in $2010 .{ }^{24}$ Conversely, we found a prevalence of $2.3 \%$ in 2005 , thus suggesting that the decline in HIV-2 may have been more rapid and possibly involved factors other than those considered in the model. The overall prevalence of HIV-2 infection in our 15-19year-old women was $0.7 \%$, and its prevalence in 2005 was $0.6 \%$, about six times less than that found by Månsson et al. in the same age group in $1995 .^{22}$ It can therefore be supposed that the HIV-2 epidemic has profoundly changed over the last $20-30$ years.

The modest genital shedding of HIV-2 and the consequent inefficiency of sexual transmission have been claimed as the main cause of the decline in HIV-2 infection in Guinea-Bissau and its disappearance in other African countries. ${ }^{1,15-18}$ This suggests that parenteral spreading was crucial at the beginning of the epidemic and a reduction in parenteral risk factors may have played a substantial role. $^{9}$

Serological data show that HIV-1 entered the country several years after HIV-2: it was absent in $1980 \mathrm{~s}^{21}$ and reached a prevalence of $6.3 \%$ in less than twenty years, which is higher than that recently reported in neighbouring countries such as Senegal (1.0\%) and Guinea Conakry (2.0\%). ${ }^{25}$ During our study period (2002-2006), the prevalence of HIV-1 infection did not significantly change, but this finding does not seem to be enough to suggest that the epidemic has now reached a steady-state.

The overall prevalence of HIV-1/HIV-2 co-infection in our study population was relatively low $(0.7 \%)$, but still sufficient to identify a significant degree of overlapping because it is about five times higher than expected if the two epidemics were fully independent: (prevalence of HIV-1) * (prevalence of HIV-2) $=0.057 * 0.024=0.0014(0.14 \%)$. These data confirm previous findings that HIV-2 infection did not protect against subsequent HIV-1 infection. ${ }^{26,27}$

Our multivariable analyses revealed an approximately $24 \%$ decrease in the risk of being co-infected $(95 \% \mathrm{Cl}$ 14-34\%) per each more recent calendar year. The phenomenon probably reflects the reduction of HIV-2 circulation in Bissau in the recent years.

Analysis of the potential factors associated with the risk of HIV infection in the population of Bissau City showed that, although they share the same routes of transmission, the two viruses have been influenced by quite different social and behavioural factors. As expected, age was an independent correlate of the risk of HIV-1 infection.

However, although the risk of HIV-1 infection was similar in the three groups of women aged $>20$ years and about twice as low in those aged 15-19 years, the risk of HIV-2 infection and HIV-1/HIV-2 co-infection was six and 8.5 times higher in the women aged $\geq 30$ years than in those aged 15-19 years, respectively.

In our study, the rate of illiteracy of $57.7 \%$ suggests that access to school has improved over the last 15 years, at least among the women living in Bissau City. ${ }^{28}$ Against our expectations, the multivariate model identified a slightly increased risk of HIV-2 infection among literate women. There is no obvious explanation for this finding, particularly as it partially conflicts with other studies, which designated a higher prevalence of HIV-2 infection in rural areas, where the rate of illiteracy is presumably higher than in the capital.

It has been reported that professional occupations, population mobility and higher socioeconomic status are associated with a higher risk of HIV-1 infection in subSaharan Africa. ${ }^{28-31}$ Although they were a minority in the enrolled population (1.7\%), women with a professional occupation were at significantly higher risk of HIV-1 infection than housewives, whereas there was no significant difference in the prevalence of HIV-2 or co-infection between the two groups. The lower risk of HIV-2 infection among students might be due to mainly urban location. This is in agreement with other studies on the same topic. ${ }^{29,31}$

In our analyses, marital status did not affect the risk of HIV infection: however, most of the women defined themselves as "amigadas", and many of those who were formally married belonged to Muslim ethnic groups in which the polygamy is very common.

The number of sexual partners during the 12 months before enrolment can be considered a factor associated with sexual transmission but, although it closely correlated 
Table 2 Adjusted analysis of the risk of being HIV-infected (polytomous logistic regression model).

\begin{tabular}{|c|c|c|c|c|c|c|c|c|}
\hline & & \multicolumn{2}{|l|}{ HIV-1 } & \multicolumn{2}{|l|}{ HIV-2 } & \multicolumn{2}{|c|}{ HIV-1/2 } & \multirow[t]{2}{*}{$p$} \\
\hline & & $\overline{O R}$ & $95 \% \mathrm{Cl}$ & $\mathrm{OR}$ & $95 \% \mathrm{Cl}$ & OR & $95 \% \mathrm{Cl}$ & \\
\hline \multicolumn{2}{|l|}{ Year of test ${ }^{a}$} & 1.02 & $0.97-1.8$ & 0.95 & $0.87-1.03$ & 0.76 & $0.66-0.86$ & 0.0003 \\
\hline \multirow[t]{4}{*}{ Age } & $15-19^{f}$ & 1 & & 1 & & 1 & & $<0.0001$ \\
\hline & $20-24$ & 1.83 & $1.50-2.23$ & 2.24 & $1.46-3.46$ & 3.19 & $1.60-6.38$ & \\
\hline & $24-29$ & 2.21 & $1.77-2.76$ & 3.34 & $2.10-5.32$ & 5.69 & $2.74-11.80$ & \\
\hline & $>30$ & 2.25 & $1.75-2.89$ & 6.38 & $3.96-10.26$ & 8.52 & $3.99-18.21$ & \\
\hline \multirow[t]{2}{*}{ Literacy } & Illiterates ${ }^{f}$ & 1 & & 1 & & 1 & & 0.301 \\
\hline & Literates & 1.13 & $0.99-1.29$ & 1.26 & $1.01-1.57$ & 0.85 & $0.59-1.21$ & \\
\hline \multirow[t]{4}{*}{ Occupation } & Housewife ${ }^{f}$ & 1 & & 1 & & 1 & & $<0.0001$ \\
\hline & Professional $^{\mathrm{b}}$ & 1.72 & $1.21-2.45$ & 0.96 & $0.50-1.84$ & 0.64 & $0.29-2.94$ & \\
\hline & Student & 1.10 & $0.88-1.37$ & 0.56 & $0.32-0.96$ & 0.83 & $0.39-1.78$ & \\
\hline & NR & 1.93 & $1.41-2.64$ & 1.44 & $0.79-2.63$ & 2.83 & $1.31-6.12$ & \\
\hline \multirow[t]{3}{*}{ Marital status } & Married $^{f}$ & 1 & & 1 & & 1 & & 0.687 \\
\hline & Amigada $^{c}$ & 1.04 & $0.91-1.19$ & 1.02 & $0.81-1.28$ & 1.03 & $0.73-1.46$ & \\
\hline & Single/NR & 1.12 & $0.92-1.38$ & 1.15 & $0.82-1.60$ & 0.68 & $0.37-1.24$ & \\
\hline \multirow[t]{3}{*}{ No sexual partners ${ }^{d}$} & $1^{f}$ & 1 & & 1 & & 1 & & 0.0005 \\
\hline & $\geq 2$ & 1.34 & $1.12-1.60$ & 1.27 & $0.96-1.69$ & 1.87 & $1.25-2.76$ & \\
\hline & $\overline{N R}$ & 1.05 & $0.86-1.29$ & 0.81 & $0.55-1.18$ & 0.85 & $0.47-1.56$ & \\
\hline \multirow[t]{12}{*}{ Ethnic group } & Balanta $^{f}$ & 1 & & 1 & & 1 & & $<0.0001$ \\
\hline & Bijagos & 0.46 & $0.24-0.87$ & 0.75 & $0.32-1.72$ & 0.36 & $0.05-2.66$ & \\
\hline & Felupe & 0.88 & $0.56-1.37$ & 0.85 & $0.39-1.84$ & 0.69 & $0.16-2.90$ & \\
\hline & Mandinga & 1.38 & $1.11-1.71$ & 1.04 & $0.71-1.54$ & 1.35 & $0.75-2.44$ & \\
\hline & Mandjaco & 0.94 & $0.73-1.21$ & 0.77 & $0.50-1.18$ & 1.24 & $0.66-2.31$ & \\
\hline & Mancanha & 1.09 & $0.85-1.40$ & 1.01 & $0.66-1.53$ & 1.44 & $0.75-2.77$ & \\
\hline & Papel & 0.74 & $0.60-0.91$ & 0.73 & $0.52-1.03$ & 0.83 & $0.46-1.48$ & \\
\hline & Fula & 1.12 & $0.93-1.35$ & 1.09 & $1.79-1.48$ & 1.50 & $0.93-2.43$ & \\
\hline & Foreigners & 1.35 & $0.77-2.37$ & 1.89 & $0.86-4.19$ & 0.85 & $0.11-6.28$ & \\
\hline & ND & 0.62 & $0.43-0.91$ & 0.92 & $0.46-1.81$ & 1.18 & $0.45-3.08$ & \\
\hline & Others ${ }^{e}$ & 1.10 & $0.83-1.46$ & 0.78 & $0.47-1.30$ & 1.68 & $0.88-3.24$ & \\
\hline & Beafada & 1.63 & $1.18-2.25$ & 2.15 & $1.33-3.49$ & 0.86 & $0.26-2.81$ & \\
\hline \multirow[t]{3}{*}{ Previous pregnancies } & $0^{f}$ & 1 & & 1 & & 1 & & 0.0080 \\
\hline & 1 & 1.29 & $1.08-1.55$ & 0.94 & $0.64-1.38$ & 1.04 & $0.60-1.79$ & \\
\hline & $\geq 2$ & 0.98 & $0.81-1.19$ & 1.26 & $0.88-1.80$ & 0.90 & $0.53-1.53$ & \\
\hline \multicolumn{9}{|c|}{$\begin{array}{l}\text { NR: not responding, OR: odds ratio, } 95 \% \mathrm{Cl}: 95 \% \text { confidential Interval. } \\
\text { a risk assessment of testing HIV positive according to the calendar year, considered as contir } \\
\text { b Including teachers, health care workers, traders, employees. } \\
\text { c Cohabitant with a stable sexual partner. } \\
\text { d In the last year. } \\
\text { e including "mixed" ethnicity and ethnic groups accounting for }<1 \% \text { of the total population. } \\
\text { f Reference categories. }\end{array}$} \\
\hline
\end{tabular}

with the risk of HIV-1 infection and HIV-1/HIV-2 co-infection, the correlation with HIV-2 infection was only of borderline statistical significance, possibly because the sexual transmission of HIV-2 is less efficient. ${ }^{1,15-18}$

In the multivariate model, the women at their second pregnancy were at significantly higher risk of being infected with HIV-1 than those at their first pregnancy, whereas the women who had experienced $\geq 2$ previous pregnancies were not. Further investigations, including timing and modality of previous deliveries, could help to confirm the role of pregnancies and deliveries as factors increasing the risk of HIV-1 transmission.

The population of Guinea-Bissau includes about 34 different ethnic groups, each with its own language, ${ }^{28}$ and cultural identity affecting personal behaviour, social life and geographical distribution. ${ }^{28}$ Both HIV-1 and HIV-2 were differently distributed among the ethnic groups. When we considered the Balanta as the reference category (the largest ethnic group accounting for $21 \%$ of the country's total population and $24.1 \%$ of our study population), it was found that the Beafadas were at greater risk of both HIV-1 and HIV-2 and Mandinga were at higher risk of HIV-1 infection. This was quite surprising because these two ethnic groups are prevalently Islamic and some studies have found that to be Muslim is a correlate of protection against HIV-1 infection. ${ }^{31,32}$ However, our findings pointed out that the risk of both HIV-1 and HIV-2 was higher in the prevalent Muslim ethnic groups which frequently practise female excision than in the groups that do not. ${ }^{33} \mathrm{Fe}-$ male circumcision takes place during an initiation ritual, the fanado. ${ }^{34}$ The Beafada usually undergo the ritual twice (usually at aged 9 and 12), whereas the women belonging to 
the other ethnic groups are circumcised only once, ${ }^{28}$ and we found that the Beafada were at highest risk for both HIV-1 and HIV-2 infections. The women participating in our study were not asked to specify whether they had been excised or not, and so we do not have any direct evidence concerning the question.

The fanado has recently been partially replaced by a 'small initiation', which is performed at an earlier age and involves smaller groups of girls, ${ }^{9,34}$ Such changes in rituals may have reduced transmission of HIV-2, but not of viruses having a more efficient parenteral transmission, such as HIV-1 and perhaps HTLV-1.

The Bijago, a prevalently Animist group living in an archipelago off Bissau City, were at lower risk of HIV-1 infection than the groups living in the mainland, and a reduced risk of HIV-1 infection has been reported in other African islands. ${ }^{30,35,36}$ The Papel, a group that traditionally lives in the urban area of Bissau, also proved to be at lower risk of HIV-1 infection, but the explanation for this will require further study.

The main purpose of our project was to provide a motherto-child transmission prevention programme and, as the collection of epidemiological data was only a secondary aim, this study may have some biases. In particular, no information was collected concerning the use of condoms, although its use seems very rare also on the basis of the data in a recent UNAIDS report. ${ }^{37}$ Furthermore, despite the large number of enrolled women, possible sampling biases include the under-representation of pregnant women aged $>35$ years; however, the reported ages were frequently unsupported by official documents and, in the opinion of the health counsellors, the women may have tended to report a younger age. Finally, the women's reports of their sexual behaviour and the number of sexual partners may have been affected by recall or reticence biases.

In conclusion, our data show that the prevalence of HIV2 infection is currently declining in Bissau City and, although currently stable, that the prevalence of HIV-1 is significantly higher than in the recent past, which could imply the possibility of a further increase in the future. Although HIV-1 and HIV-2 share the same transmission routes, our data suggest that the overlapping of the two epidemics is only partial.

The rapid decline in the rates of HIV-2 infection suggests that many of the factors that allowed its exponential growth in the past have now been partially removed, and that sexual and vertical transmission have not been sufficient to maintain and extend the epidemic.

\section{Acknowledgements}

The study was carried out by a Guinean NGO (Céu e Terras) in collaboration with the University of Milan's Institute of Infectious and Tropical Diseases (now the Infectious Diseases and Immunopathology Section of the Department of Clinical Sciences). Financial support was provided by an Italian NGO (Cielo e Terre, Milan), the Lombardy Section of the Italian National Association against AIDS (ANLAIDS), Milan City Council, the ICAV Study (Italian concerted action for the development of a vaccine against HIV/AIDS; grants 45F17 and 45G14), the Esther Program "Esemble pour une solidarité therapeutique hospitaliere en reseau contre le SIDA", Agreement No. 521E/2-XIV between L. Sacco Hospital and the Istituto Superiore di Sanità, Rome, and L. Sacco Hospital Resolution No. 126 of 10 February 2004.

We are indebted to Dr. Placido Monteiro Cardoso (General Direction of the Ministry of Health of GuineaBissau in 2007) for his fundamental suggestions and revision, and to Prof. Piergiorgio Duca for the statistical analyses.

\section{Ethical approval}

The scientific committee of the Ministry of Public Health in Guinea-Bissau granted permission to conduct the study.

\section{Conflict of interest}

The authors declare that they have no conflict of interest.

\section{References}

1. Schim van der Loeff $M$, Aaby P. Towards a better understanding of the epidemiology of HIV-2. AIDS 1999;13(Suppl. A):S69-84.

2. Poulsen AG, Kvinesdal B, Aaby P, Mølbak K, Frederiksen K, Dias F, et al. Prevalence of and mortality from human immunodeficiency virus type-2 in Bissau, West Africa. Lancet 1989;i: 827-31.

3. Holmgren B, da Silva Z, Larsen O, Vastrup P, Andersson S, Aaby P. Dual infection with HIV-1, HIV-2 and HTLV-1 are more common in older women than in men in Guinea Bissau. AIDS 2003; 17:241-53.

4. Sarfo FS, Bibby DF, Schwab U, Appiah LT, Clark DA, Collini P, et al. Inadvertent non-nucleoside reverse transcriptase inhibitor (NNRTI)-based antiretroviral therapy in dual HIV-1/2 and HIV-2 seropositive West Africans: a retrospective study. J Antimicrob Chemother 2009;64:667-9.

5. Lemey P, Pybus OG, Wang B, Saksena NK, Salemi M, Vandamme A. Tracing the origin and history of the HIV-2 epidemic. Proc Natl Acad Sci U S A 2003;100:6588-92.

6. Poulsen AG, Aaby P, Larsen $O$, Jensen H, Nauclér A, Lisse IM, et al. 9-year HIV-2 associated mortality in an urban community in Bissau, west Africa. Lancet 1997;349:911-4.

7. Aaby P, Ariyoshi K, Buckner M. Age of wife as a major determinant of male-to-female transmission of HIV-2 infection: a community study from rural West Africa. AIDS 1996;10:1585-90.

8. Lasen O, da Silva Z, Sandstrom A, Andersen PK, Andersson S, Poulsen AG, et al. Declining HIV-2 prevalence and incidence among men in a community study from Guinea-Bissau. AIDS 1998;12:1707-14.

9. Pepin J, Plamondon M, Alves AC, Beaudet M, Labbé A. Parenteral transmission during excision and treatment of tuberculosis and trypanosomiasis may be responsible for the HIV-2 epidemic in GuineaBissau. AIDS 2006;20:1303-11.

10. Ministerio de Saúde Pública. Programa Nacional de Luta contra o SIDA (PNLS). Plano estratégico nacional de Luta contra o SIDA (2003-2005). Republica da Guiné Bissau.

11. da Silva ZJ, Oliveira I, Andersen A, Dias F, Rodrigues A, Holmgren $B$, et al. Changes in prevalence and incidence of HIV-1, HIV-2 and dual infection in urban areas of Bissau, Guinea Bissau: is HIV-2 disappearing? AIDS 2008;22:1195-202.

12. Van Tienen C, Schim van der Loeff MF, Zaman SM, Vincent T, Sarge-Njie R, Peterson I, et al. Two distinct epidemics: the rise of HIV-1 and decline of HIV-2 infection between 1990 and 2007 in rural Guinea-Bissau. J Acquir Immune Defic Syndr 2009;53:640-7. 
13. Schim van der Loeff MF, Larke N, Kaye S, Berry N, Ariyoshi K, Alabi A, et al. Undetectable plasma viral load predicts normal survival in HIV-2-infected people in a West African village. Retrovirology 2010;19:7-46.

14. Rowland-Jones SL, Whittle HC. Out of Africa: what can we learn from HIV-2 about protective immunity to HIV-1? Nat Immunol 2007;8:329-31.

15. Kanki PJ, Travers KU, Marlink RG, Essex ME, M'Boup S, Gueye-NDiaye A, et al. Slower heterosexual spread of HIV2 than HIV-1. Lancet 1994;343:943-6.

16. De Cock K, Adjorlolo G, Ekpini E, Sibailly T, Kouadio J, Maran M, et al. Epidemiology and transmission of HIV-2. Why there is no HIV-2 pandemic. J Am Med Assoc 1993;270:2083-6.

17. Hawes SE, Sow PS, Stern JE, Critchlow CW, Gottlieb GS, Kiviat NB. Lower levels of HIV-2 than HIV-1 in the female genital tract: correlates and longitudinal assessment of viral shedding. AIDS 2008;22:2517-25.

18. Ghys PD, Fransen K, Diallo MO, Ettiegne-Traore V, Coulibaly IM, Yeboue KM, et al. The association between cervicovaginal HIV shedding, sexually transmitted disease and immunosuppression in female sex workers in Abidjan, Côte d'Ivoire. AIDS 1997;11: F85-93.

19. Carr J, Salminen MO, Albert J, Sanders-Buell E, Gotte D, Birx DL, et al. Full genome sequences of human immunodeficiency virus type 1 subtypes $G$ and $A / G$ intersubtype. Recombinants Virol 1998;247:22-31.

20. Andersson S, Norrgren H, Dias E, Biberfeld G, Albert J, et al. Molecular characterization of human immunodeficiency virus (HIV)-1 and -2 in individuals from Guinea-Bissau with single or dual infections: predominance of a distinct HIV-1 subtype A/G recombinant in West Africa. Virology 1999;262:312-20.

21. Piedade J, Venenno $T$, Prieto $E$, Albuquerque R, Esteves $A$, Parreira R, et al. Longstanding presence of HIV-2 infection in Guinea Bissau (West Africa). Acta Trop 2000;76:119-24.

22. Månsson $F$, Alves $A$, da Silva ZJ, Dias F, Andersson $S$, Biberfeld G, et al. Trends of HIV-1 and HIV-2 prevalence among pregnant women in Guinea Bissau, West Africa: possible effect of the civil war 1998-1999. Sex Transm Infect 2007;83:463-7.

23. UNAIDS/WHO. Policy on HIV testing; June 2004.

24. Schmidt WP, Schim van der Loeff $M$, Aaby $P$, Whittle $H$, Bakker R, Buckner M. Behaviour change and competitive exclusion can explain the diverging HIV-1 and HIV-2 prevalence trends in Guinea Bissau. Epidemiol Infect 2008;136:551-61.
25. Unaids. AIDS epidemic update 2009, http://data.unaids.org/ pub/Report/2009/2009_epidemic_update_en.pdf [accessed 09.12.09].

26. Norrgren $\mathrm{H}$, Andersson $\mathrm{S}$, Biague AJ, da Silva ZJ, Dias $\mathrm{F}$, Naucler A, et al. Trends and interaction of HIV-1 and HIV-2 in Guinea Bissau, West Africa: non protection of HIV-2 against HIV-1 infection. AIDS 1999;13:701-7.

27. Schim van der Loeff MF, Aaby $P$, Ariyoshi K, Vincent $T$, Awasana AA, Da Costa C, et al. HIV-2 does not protect against HIV-1 infection in a rural community in Guinea Bissau. AIDS 2001;15:2303-10.

28. World Bank. Republic of Guinea Bisssau, Poverty assessment and social Sectors, http://www-worldbank.org; 1994.

29. Lydié N, Robinson NJ, Ferry B, Akam E, De Loenzien M, Abega S. Mobility, sexual behaviour, and HIV infection in an urban population in Camerun. J Acquir Immune Defic Syndr 2004; 35:67-74.

30. Msisha WM, Kapiga SH, Earls F, Subramamian SV. Socioeconomic status and HIV seroprevalence in Tanzania: a counterintuitive relationship. Int J Epidemiol 2008;37:1297-303.

31. Croce F, Fedeli P, Dahoma M, Deho L, Ramsan M, Adorni F, et al. Risk factors for HIV/AIDS in a low prevalence site of sub-Saharian Africa. Trop Med Int Health 2006;12:1-6.

32. Gray PB. HIV and Islam: is HIV prevalence lower among Muslims? Soc Sci Med 2004; 13:467-85.

33. Yoder PS, Khan S. Numbers of women circumcised in Africa: the production of a total. In: DHS (demographic and health research) working paper, vol. 39. USAID; March 2008.

34. Johnson MC. Becoming a Muslim, becoming a person: female 'circumcision', religious identity, and personhood in Guinea Bissau. In: Shell-Duncan B, Hernlund Y, editors. Female 'circumcision' in Africa. Culture, controversy and change. Boulder: Lyenne Rienne Publisher; 2000. p. 215-33.

35. Jensen HA, Morrison L, Mosha F, Changalucha J, Todd J, Obasi A, et al. Geographical variations in the prevalence of HIV and other sexually transmitted infections in rural Tanzania. Int J STD AIDS 2003;14:274-80.

36. Joint United Nations Program on HIV/AIDS. Epidemiological fact sheets on HIVIAIDS and sexually transmitted infections: Comoros, Seychelles, Madagascar, Mauritius; 2004. Geneva, Switzerland.

37. UNAIDS global report, www.unaids.org/en/; 2008 [accessed 22.11.09]. 